\title{
Evaluation of dietary risk in a sample of pre-school children (12-36 months) using a validated nutrition screening tool
}

\author{
K. Flynn ${ }^{1}$, J.L. O’Neill ${ }^{2}$, N. Brannelly ${ }^{2}$, E. Shannon ${ }^{2}$ and A. Regan ${ }^{2}$ \\ ${ }^{1}$ UCD Institute of Agriculture and Food Science, University College Dublin, Belfield, Dublin 4, Republic of Ireland and \\ ${ }^{2}$ Danone Nutricia Early Life Nutrition, Block 1 Deansgrange Business Park, Deansgrange, Co. Dublin, Republic of \\ Ireland
}

The diet in the early years is critical to provide the nutrients needed to support optimal growth and development in young children ${ }^{(1)}$. The National Preschool Nutrition survey reported inadequate intakes of iron and vitamin D among Irish pre-school children. $23 \%$ of 1 year olds and $10 \%$ of 2 and 3 year olds had inadequate intakes of iron. Furthermore, $70-84 \%$ of $1-4$ year olds had an intake of vitamin D less than $5 \mu \mathrm{g} / \mathrm{d}^{(2)}$

The aim of this study was to identify dietary risk factors in a sample of pre-school children aged $12-36$ months. This was assessed using a validated dietary risk screening tool (NutriCHEQ) ${ }^{(3)}$. The NutriCHEQ screening tool is in the form of a 19 item questionnaire.

Parents/guardians completed an online version of the questionnaire. Dietary risk was rated on a scale ranging from $0-22$ from 11 questions. On the basis of their risk score, the individuals were allocated into high, moderate or low risk ${ }^{(3)}$ and provided with tailored educational booklets where necessary.

The mean age of the sample was 22 months. This study found that $71 \%$ were moderately at risk of having low intakes of iron, vitamin D and zinc. $37 \%$ had a moderate/high risk of having dietary imbalances (e.g. adequate dairy, fruit, and vegetables intakes).

Although a large proportion of parents/guardians considered their child's diet as healthy $(97 \%)$, over half the pre-school children in

\begin{tabular}{lccc}
\hline & \% Risk & & \\
\cline { 2 - 4 }$(\mathrm{n}=698)$ & High & Moderate & \\
\hline Low iron stores/low intake of iron (\& vitamin D, zinc) & 19 & 71 & Low \\
Dietary imbalance & 4 & 33 & 10 \\
Combined overall risk $^{t}$ & 3 & 60 & 63 \\
\hline
\end{tabular}

${ }^{\mathrm{I}}$ Risk of low iron stores, low intake of vitamin $\mathrm{D}$, zinc \& dietary imbalances

this sample were moderately at risk (60\%) of having low intakes of iron, vitamin D, zinc and dietary imbalances. This study shows that an online version of the NutriCHEQ screening tool can be useful for healthcare professionals to identify dietary risk factors in pre-school children.

1. Langley-Evans S. Nutrition in early life and the programming of adult disease: a review. Journal of Human Nutrition and Dietetics. 2014;28:1-14.

2. Irish Universities Nutrition Alliance. National Preschool Nutrition Survey Main Report. Available from: www.iuna.net; 2012.

3. Rice N, Gibbons H, McNulty B, Walton J, Flynn A, Gibney M et al. Development and validation testing of a short nutrition questionnaire to identify dietary risk factors in preschoolers aged 12-36 months. Food Nutr Resear. 2015;59(0). 